\title{
A NOTE ON THE DOG'S TAPETUM IN EARLY LIFE*
}

BY

\author{
C. H. Usher \\ ABERDEEN
}

This note is written for the purpose of pointing out that the tapetum of the dog is not recognizable ophthalmoscopically for several weeks after birth, and that the early ophthalmoscopic appearances of the tapetum differ markedly from those seen in the adult animal.

A considerable search through ophthalmological and veterinary literature and conversation with some ophthalmologists, zoologists, and veterinary workers, has convinced me that these points are at least not generally known, though it seems unlikely that there is no record of them somewhere in literature.

The present observations were made on the eyes of puppies from ten different litters. In some cases only a single examination was made, in others an examination was made every week.

Observation 1. My attention was first drawn to the subject when making an ophthalmoscopical examination of the fundus of a five weeks old puppy, which to my surprise showed no evidence of a tapetum. When examined again at the age of ten weeks there was a well marked iridescent tapetum.

Observation 2. In a puppy from another litter no sign of a tapetum was present on the 20th, 38th, and 44th days after birth, but, on the 49 th day there was a delicate diffuse purple in the tapetal area, most pronounced at its lowest part, though not sufficient to obscure the choroidal vessels. Two weeks later a green colouration was seen amongst the purple. By the 71st day the tapetum was markedly green resembling that of the adult dog and no choroidal vessels were visible at this region, whereas, by the end of the fifth week these vessels were as conspicuous in the tapetal area as they were in the lower part of the fundus.

Observation 3. Five liver and white pointer puppies were examined when three weeks old. Not one of the eyes showed any evidence of a tapetum. Two of the puppies, a male and a female, were re-examined on the 61st day and found to have a brilliant tapetum with purple predominating.

Observation 4. A second litter of five liver and white pointer puppies, four females and one male, examined on the 33rd day after birth showed no evidence of a tapetum in any of their eyes.

Observation 5. A litter of three male pointer puppies, one black

* Throughout this paper " tapetum " refers to the tapetum lucidum. 
and white, the other two liver and white, showed no signs of a tapetum in any of the eyes on the 33rd day after birth.

Observation 6. 'A black and white pointer, aged 26 days, ophthalmoscopically showed no evidence of a tapetum. Left eye only examined.

Observation 7. An English, setter, black and white, aged 35 days, showed no evidence of a tapetum.

Observation 8. Bulldog puppies, white and brindle, three females and and one male. No tapetum was visible in any of the eyes when examined on the 22nd and 29th days after birth. Thirty-six days after birth one bitch had no colour in the tapetum, and the other two bitches showed a very faint green tinge; the dog puppy.had a distinctly green coloured tapetum. On the 50th day the tapetum was greenish blue in all of the eyes. The pupils were dilated by a mydriatic on each occasion.

Observation 9. A litter of three. (Dam a pomeranian probably not pure, sire pomeranian with some admixture of pekinese some generations before.) $\mathrm{A}$, a female with dark brown coat. B, a male, coat colour same as that of A. C, a male, with white coat. No tapetum was found in any of them 22 and 29 days after birth. On the latter date puppy $B$ was killed and one eye opened equatorially. The fundus macroscopically showed no sign of a tapetum, and the vitreous and lens were quite clear. Puppies A and $\mathrm{C}$ were re-examined on the $36 \mathrm{th}$ and $43 \mathrm{rd}$ days, when there was again no sign of tapetal colouring. On the 50th day, puppy A had just a suspicion of purple in the upper part of the fundus, and puppy $\mathrm{C}$ had marked patches of purple in the same region of each eye. There was no green or yellow colouring. Seven days later the purple was intense in the tapetum of puppy $\mathrm{C}$, and though quite definite it was less brilliant in the tapetum of puppy A. By the 64th day there were bright green spots amongst the purple, and in places the purple had a redder appearance. These appearances were seen in the tapetum of . both puppies. By the 71st day there was much more green in the tapetum, which was altogether more brilliant and its lower margin was better defined than it was one week before. In puppy $\mathrm{C}$ the green colour had replaced much of the purple colour. By the 99th day in each puppy the tapetum was brilliant green spotted with yellow. The upper parts were paler and presented more yellow colouration.

Observation 10. A Scottish terrier bitch mated with a black pomeranian dog had a litter of four. Puppy A, male, coat black. Puppy B, male, coat black with white spot on chest. Puppy C, male, coat black. Puppy D, female, coat black. Puppies A and B were examined 26 days, 33 days, and 40 days after birth. On none of these occasions was there any evidence of a tapetum in 
the eyes of ,either puppy, the upper part of the fundus having the same appearance as the lower part. On the 47 th day all the puppies were examined and in each case there was a marked purple colour at the tapetal region. No green had appeared excepting a single small spot in one of the eyes of puppy B. By the 54th day there was a considerable quantity of green amongst the purple in each of the eight eyes. On the 61st day the tapetum, in each of the four puppies, was still, in some parts; more purple than green, in other parts the green predominated. On the 75th day : in puppy $A$ the tapetum was purple and green in equal quantities, each colour being arranged in small patches; there was no yellow. In puppy B, the tapetum was principally green with some yellow especially above, and there was a little purple anteriorly. In puppy $\mathrm{C}$, the tapetum was mostly green with some purple, and in puppy $\mathrm{D}$, the tapetum had rather more green than purple, but there was no yellow in either. The last examination was made on the 89th day, when in all of the puppies the tapetum was brilliant green with small yellow spots, which in puppies $A$ and $D$ were scanty and very small. At the edge of the tapetum was some purple. 'The examinations were made with pupils dilated by homatropin, and an oil lamp was used.

As regards the length of time that elapses, from the date of birth, before the tapetum begins to assume its brilliant colouration it will be seen that an ophthalmoscopic examination of the eyes of 17 puppies in their fifth week showed no evidence of a tapetum, and in eight puppies examined before the fifth week no tapetum could be seen. For the purpose of determining when the tapetum first becomes recognizable only four of the observations are available, namely, $2,8,9$, and 10 . In observation 2 , signs of the tapetum were seen on the 49 th day. These were not present five days earlier. In observation 9 , the first signs were seen on the 50 th day. These were not present one week earlier. In observation 10, the first signs were seen on the 47 th day. These signs were not present one week earlier. In these three litters then, the colouring of the tapetum in the seven puppies' eyes was visible for the first time from the 47 th day to the 50 th day, and in two of these litters (observations 2 and 9 ) it certainly was not present before the seventh week, and in the third litter (observation 10) before the 40th day. The onset of the colouration in (observation 8) the bulldog puppies, occurred earlier, namely, at the beginning of the sixth week, for three of the four puppies showed a faint green in the tapetal region on the 36th day. No colouration had been observed one week earlier. The early colouring was different in this litter from that in other litters, but it is possible that purple had appeared and had been replaced by green, within a week, during which time no examination was made. 
The earliest colour to appear in the tapetum, as seen from these observations, is a beautiful purple which before long is gradually replaced by a brilliant pale green in which, later, spots of yellow develop. The margin of the tapetum remains purple. It may be that the above sequence of colours varies to some extent in different breeds as the litter of bulldog puppies suggests, in which the first colour seen was pale green.

A short account of what obtains in the case of the cat's tapetum is here added. In 1871, Schultze ${ }^{(1)}$ recorded absence of metallic lustre in the choroid of the cat two weeks after birth. In 1884 , Hilbert ${ }^{(2)}$ examined a kitten's fundus ophthalmoscopically at frequent intervals. His description appears to be the only account of the early ophthalmoscopic appearances of the tapetum in the cat, 'and is founded on the examination of a single kitten. $\mathrm{He}$ found that a yellow colouration preceded the subsequent blue and violet.

The tapetum of the cat resembles that of the dog in that there is no ophthalmoscopic evidence of its presence during the first few weeks of life, and in that the green colour of the tapetum of the adult cat is preceded by a diffuse purple colouration of the whole of the tapetum. These remarks are based on the examination of kittens from four litters.

(1) A black female kitten examined when 14 days and again when 16 days old showed a uniform grey appearance of the fundus with no difference at the tapetal region. There was no red, blue, yellow, green or purple colouration. There was no change in the appearance of the fundus on the 27th day and 36 th day. Unfortunately, the kitten died on the 40th day. Another black coated kitten from the same litter on the 48th day had a brilliant green, yellow, and purple tapetum in each eye.

(2) Two black kittens, a male and a female, from the same litter, were examined on the 32nd day after birth. All the eyes presented a diffuse delicate purple colour in the upper part of the fundus. The lower part of the fundus did not show a good red colour, but had rather a greyish aspect. On the 46th day the colouring of the tapetum was more pronounced. The deepest purple was at its lower edge, whereas above, the tapetum became very pale with a tinge of green. The fundus below was dark red. The female kitten at the end of six months had a brilliant green tapetum.

(3) Two female kittens from the same litter, one with a yellow coat, the other with a brown and black tigroid coat, were examined on the 25th day after birth, when no evidence of a tapetum was present. The whole fundus had a reddish grey aspect. On the 29th day there was a distinct diffuse purple over the tapetum in all of the eyes. Some redness was seen at the lower part of the 
fundus. On the 39th day the tapetum had a brilliant purple colour becoming fainter, almost white, above. No green colour was found in any of the eyes. On the 46th day, there was green colouration of much of the tapetum. Purple was marked at the lower edge. On the 60th day the tapetum was pale green except at the edge where there was a narrow zone of purple. The lower part of the fundus was brownish red.

(4) Three kittens from the same litter. Iris greenish blue in all. First examination on the 30th day. A, a grey-coated, male kitten. The fundus had a grey appearance, and the lower part had the same appearance as the tapetal portion on indirect examination, but, on direct examination a faint tinge of purple was detected in the tapetum, mostly at the upper part. B, a blackcoated, female kitten. The merest trace of purple could be detected, chiefly at the upper part of the tapetum. C, a blackcoated female kitten, with a tapetum resembling that in kitten B. On the 38th day, the three kittens showed very marked purple colouration of the tapetum, especially at the lower part. The upper part was paler. The fundus below the tapetum was grey with a tinge of red. On the 48th day the tapetum of each kitten had a brilliant green colour like that seen in X-ray tubes, but the lower part showed much purple. The examinations were made after the use of a mydriatic, and an oil lamp was used.

In comparing these results with what was found in the puppies, it would appear that generally the colour of the tapetum is later in appearing in the dog than in the cat. In three of the cat litters purple was observed from the 29th day to the 32 nd day, in the remaining litter there was no colouration on the 36th day, whereas in the dog the earliest appearance of colour was on the 36th day, namely, one week later than the earliest occurrence in the kittens, and the more usual date in the dog was from the 47 th to the 50 th day, that is, more than two weeks later than in the kittens. Without exception, purple was the first distinctive tapetal colour to appear in the kitten.

The correlation of these early ophthalmoscopic appearances of the tapetum with the histological changes that occur in the iridocytes, as described by Schultze and others, is of interest, but, the subject is outwith the scope of this note.

\section{REFERENCES}

1. Schultze, M.- "Ueber das Tapetum in der Chorioides der Raubthiere." Sitzungsberichte der. Niederrheinischen Gesellsch. f. Natur und Heil. kunde, Nachtrag zum Bericht über der Sitzung, von November 27, 1871. Original not seen. Ref. Nagel's Jahresbericht, p. 45, 1871.

2. Hilbert, Richard.- " Ueber die nach der Geburt eintretenden entwickelungsgeschichtlichen Veränderungen der brechenden Medien und des Augenhintergrundes der Katze." Arch.f. Ophthal., Vol. XXX, No. 3, p. 245, 1884 . 